\title{
SUPPLEMENT
}

\author{
Esra Temugan ${ }^{1}$ \\ Rabia B. Yildirtm ${ }^{I}$ \\ Hümeyra Onat ${ }^{1}$ \\ Merve Susuz ${ }^{1}$ \\ Cemre Elden ${ }^{I}$ \\ Selim Unsal ${ }^{1}$ \\ Nebi Mustafa Gumus ${ }^{3}$ \\ Mesut Kaya ${ }^{2}$
}

${ }^{1}$ Turgut Ozal University, School of Health, Department of Audiology, Ankara, Turkey 2Turgut Ozal University, Faculty of Medicine, Department of Otolaryngology, Ankara, Turkey

${ }^{3}$ Turgut Ozal University, Vocational Health School, Department of Audiometry, Ankara, Turkey

\section{Does Tinnitus Lead to Depression?}

\begin{abstract}
Purpose: The aim of the study was to investigate the correlation between THI (Tinnitus Handicap Inventory) and BDS (Beck Depression Scale).

Materials and Methods: High frequency thresholds and PTA (Pure Tone Audiometer) thresholds for the patients were measured in 44 patients with tinnitus (bilateral=13; unilateral=31). Tinnitus frequency and intensity were measured using one-pair method with high frequency audiometer Interacoustic AC40. Applied BDS and THI scores are evaluated for all patients. Our findings are analysed statistically with SPSS v.21 and BDS and THI correlation with tinnitus intensity and frequency was executed.

Results: The mean value of tinnitus frequency was $10 \mathrm{kHz}(\min 0.25 \mathrm{kHz}, \max 16 \mathrm{kHz}$ and SD 4.26), mean tinnitus intensity was $50.6 \mathrm{~dB}$ (min $15 \mathrm{~dB}$, max $110 \mathrm{~dB}$ and SD 26.9 $\mathrm{dB}$ ) mean THI score was 38.04 ( $\min 10$, $\max 86$ and SD 20.03) and mean BDS score was 9.45 ( $\min 0$, $\max 28$ and SD 6.49). There was no statistical correlation between THI score and tinnitus frequency $(\mathrm{r}=0.055, \mathrm{p}=0.787)$. Moderate correlation is obtained between tinnitus frequency and depression $(\mathrm{r}=0.6, \mathrm{p}=0.001)$. There were weak correlations between tinnitus intensity and THI score and $(\mathrm{r}=0.3, \mathrm{p}=0.09)$ and between tinnitus intensity and BDS score $(\mathrm{r}=0.28, \mathrm{p}=0.13)$. Although a statistically significant difference was observed between THI scores of patients with bilateral and unilateral tinnitus $(p<0.05)$, BDS scores of these groups were not statistically different from each other $(p>0.05)$. High frequency thresholds and UCL scores of ears with tinnitus were not statistically different from ears with no tinnitus $(p>0.05)$.
\end{abstract}

Conclusion: No correlation was seen between THI and tinnitus frequency, but a moderate correlation was seem between BDS score and tinnitus frequency. There were also weak correlations between tinnitus intensity and THI and BDS scores. 
Tinnitus is an otological and neurotological symptom that is described as perception of sound when there is no external stimulus. Patients define tinnitus as ringing buzzing, whistling or humming in their unilateral or bilateral ears or into their head [1-3]. Tinnitus is most prevalent at $40-80$ years of age, with $17 \%$ of the general population and $33 \%$ of the geriatric population complaining of tinnitus [4].

The pathophysiology of tinnitus is not precisely understood [5], and many ideas have been put forward for the physiological mechanism of tinnitus; however, all of the suggested mechanisms of pathogenesis are based on a spontaneous increase in the activity at the nerve fibrils $[4,6]$.

Many studies in literature have shown that acoustic evaluations alone are not sufficient for assessment of tinnitus. Psychosomatic tests must also be carried out for patients with tinnitus [7]. THI (Tinnitus Handicap Inventory) is one of the most commonly used tests. Wilson et al. first described the scale [8] and Aksoy et al. subsequently translated it into Turkish. THI assesses the emotional, functional and catastrophic effects of tinnitus on the patients [7]. The inventory consists of 25 items and each item has three answer options: yes: 4 points, sometimes: 2 points, no: 0 points. Thus, score ranges from 0 to 100 [9].

Depression is a kind of syndrome or disease that is related to psychological breakdown. Some studies associate depression with tinnitus at the molecular level, and these studies have shown that similarities exist in the molecular mechanisms of the two diseases. The most obvious similarly for both diseases is the serotonin mechanism disorder. Deniz et al. showed the significance of the serotonin mechanism in tinnitus and pointed out the similarity with depression [10]. It is known that one of the psychosomatic effects of tinnitus is the presence of psychological disorders, like depression. Depression may cause tinnitus or vice versa. BDS is one of the scales used for assessing the level of depression for the patients with tinnitus. Produced by Beck in 1961, the scale was rewritten at 1971 and it published in 1978 [10]. The scale consists of 25 items and the higher the points, higher the depression level. The scale is executed with clinical observations [10].

Perception of tinnitus differs from patient to patient. There are four significant methods for objective assessment of tinnitus: 1 . measuring tinnitus frequency [11]; 2. measuring tinnitus intensity [11]; 3. investigating masking level of tinnitus [12]; and, 4. residual inhibition [13]. These data provide knowledge to physicians about the psychoacoustic properties of tinnitus. These data also help the physician to choose appropriate therapeutic techniques and to monitor the results of the treatment [14]. There are multiple methods for evaluating tinnitus frequency and intensity. Schulman, for example, investigated the 'one pair method' and asked the patients to choose the most similar tone after providing two different tone stimuli. Vernan confirmed that this method was reliable [15]. Miguel et al. compared the tinnitus intensity and frequency levels that are measured with a conventional audiometer and a high frequency audiometer. They showed that tinnitus frequency measured with high frequency audiometer is higher than the measurement with the aid of standard audiometer [14]. In our study we measured the tinnitus frequency and intensity with high frequency audiometer and compare the results with BDS and THI scores.

\section{Materials and Methods}

The study took place in the Clinic of Audiology and Speech Disorders at the University of Turgut Ozal Faculty of Medicine Hospital. This research has been approved by the Ethics Committee for Clinical Research of the Turgut Ozal University Medical School.

Seventy volunteer patients, complaining tinnitus, who consulted the ENT Clinic of Turgut Özal University Beştepe Hospital, participated in this study. Forty four patients (female $=26$; male $=18$ ) between the ages of 18-65 years (mean age $=42.4 \pm 15.2$ years, $\min =20$ years, $\max =65$ years), who complained of tinnitus for a minimum of three months (mean period= 17.8 months min 3 months; max. 84 months), had normal cognitive levels and normal outer and middle ear function with Tip A tympanogram, and no history of ear infections in the preceding month, were included in this study.

PTA (Pure Tone Audiometer) thresholds at $250 \mathrm{~Hz}-$ $6000 \mathrm{~Hz}$ frequency range were obtained with Interacoustics AC-40 audiometer (Interacoustics A/S, Middelfart, Denmark). High frequency thresholds $(8000 \mathrm{~Hz}, 12000 \mathrm{~Hz}$ and $16000 \mathrm{~Hz}$ ) were also measured in the same equipment. UCL (Uncomfortable Level) was obtained for all the patients by asking the patients to identify an uncomfortable level of sound with a speech stimulus.

We determined each patient's tinnitus frequency and intensity using the 'one-pair method'. THI, consisting of 21 items, and BDS, consisting of a 25 items questionnaire were administered to each patient and THI and BDS scores were calculated.

Statistical analyses were performed with IBM SPSS v.21. Normal distribution of the data was controlled with normality tests. The tinnitus frequency and intensity levels correlations with THI and BDS scores were analysed with Pearson Correlation test. Independent sample t-tests were used for comparing THI and BDS scores of unilateral and bilateral 
TABLE 1. Classification of BDS scores

\begin{tabular}{l|c}
\hline Point Range & Classification of BDS \\
\hline $1-10$ & normal \\
\hline $11-16$ & slight psychological breakdown \\
\hline $17-20$ & borderline clinic depression \\
\hline $21-30$ & moderate depression \\
\hline $31-40$ & serious depression \\
\hline$>40$ & very high depression \\
\hline
\end{tabular}

TABLE 2. Correlation between THI and tinnitus frequency

\begin{tabular}{l|c|c|c|c}
\hline & Mean & \pm SD & $\mathbf{r}^{*}$ & $\mathbf{p}^{*}$ \\
\hline Tinnitus frequency & 10.33 & 4.49 & 0.053 & 0.787 \\
\hline THI & 37.84 & 19.45 & & \\
\hline
\end{tabular}

*Pearson Correlation test results

TABLE 3. Correlation between BDS and tinnitus frequency

\begin{tabular}{l|c|c|c|c}
\hline & Mean & \pm SD & $\mathbf{r}^{*}$ & $\mathbf{p}^{*}$ \\
\hline Tinnitus frequency & 10.33 & 4.49 & 0.59 & 0.001 \\
\hline BDS & 8.95 & 6.78 & & \\
\hline
\end{tabular}

* Pearson Correlation test results

TABLE 4. Correlation between tinnitus intensity and THI, BDS

\begin{tabular}{l|c|c|c|c}
\hline & Mean & $\pm \mathbf{S D}$ & $\mathbf{r}^{*}$ & $\mathbf{p}^{*}$ \\
\hline Tinnitus intensity & 51.32 & 29.48 & & \\
\hline THI & 37.84 & 19.45 & 0.31 & 0.09 \\
\hline BDS & 8.95 & 6.78 & 0.28 & 0.13 \\
\hline
\end{tabular}

* Pearson Correlation test results

TABLE 5. THI and BDS scores of patients with unilateral and bilateral tinnitus

\begin{tabular}{l|c|c|c|c}
\hline & Tinnitus & Mean & $\pm S D$ & \multirow{2}{*}{$\mathbf{p}^{*}$} \\
\hline \multirow{2}{*}{ THI } & unilateral & 32.67 & 18.42 & \multirow{2}{*}{0.00} \\
\cline { 2 - 4 } & bilateral & 51.50 & 18.01 & \\
\hline \multirow{2}{*}{ Beck } & unilateral & 8.67 & 6.32 & \multirow{2}{*}{0.22} \\
\cline { 2 - 4 } & bilateral & 11.42 & 6.79 & \\
\hline
\end{tabular}

* Independent Sample t- test results tinnitus. Paired sample t-tests were also done for comparing ears of the patients with unilateral tinnitus. PTA thresholds and UCL scores of the ear with tinnitus and no tinnitus were analyzed statistically.

\section{Results}

Forty-four volunteer patients, 13 of the patients with bilateral tinnitus and 31 of the patients with unilateral tinnitus, participated in the study. Mean tinnitus frequency was $10 \mathrm{kHz}$ (min $0,25 \mathrm{kHz}, \max 16 \mathrm{kHz}$ and SD 4.26), mean intensity of tinnitus was $50.6 \mathrm{~dB}(\min 15 \mathrm{~dB}, \max 110 \mathrm{~dB}$ and SD 26.9 $\mathrm{dB}$ ). Mean THI score was $38.04(\min 10, \max 86$ and SD 20.03 ) and mean BDS score was $9.45(\min 0, \max 28$ and SD 6.49).

All correlations were assessed with Pearson correlation test. There was a weak correlation between THI and BDS and it is not statistically significant $(\mathrm{r}=0.271)(\mathrm{p}=0.82)$. There was also any correlation between THI and tinnitus frequency $(\mathrm{r}=0.053)$ meaning that tinnitus frequency did not affect the handicap level (Table 2). There was a moderate correlation between BDS and tinnitus frequency and this correlation was statistically significant $(\mathrm{r}=0.6) \quad(\mathrm{p}=0.001)$ (Table 3). In other words, increasing levels of tinnitus frequency lead to increasing depression scores, as seen in Figure 1.

The correlation between THI and tinnitus intensity was weak and not statistically significant $(\mathrm{r}=0.3) \quad(\mathrm{p}=0.09)$. Similarly, the correlation between BDS and tinnitus intensity was weak and not statistically significant too $(r=0.28)(p=0.13)$ (Table 4). Statistical analyses also show that THI scores of the patients with bilateral tinnitus and unilateral tinnitus are significantly different from each other $(\mathrm{p}<0,05)$. The effect of having unilateral and bilateral tinnitus is not seen statistically significant for BDS scores ( $p>0,05)$ (Table 5).

When we compared PTA thresholds and UCL scores of the patients with unilateral tinnitus, the ears with tinnitus and the ears with no tinnitus were not different from each other (Table 6)

\section{Discussion}

Tinnitus is seen $17 \%$ of general, $33 \%$ of geriatric population [4] and it has similar prevalence as regards to gender. Tinnitus is a serious illness for $13 \%$ of the patients with tinnitus [15]. The pathology is associated with the auditory cortex, neurons, structures near the cochlea and central nervous system. Anxiety and depression symptoms are often comorbid to tinnitus, and are affected from serotonin and GABA receptors. 
TABLE 6. Comparison of PTA, high frequency thresholds and UCL scores

\begin{tabular}{|c|c|c|c|c|c|}
\hline & Tinnitus & $\mathrm{N}$ & Mean & $\pm \mathrm{SD}$ & $\mathrm{p}^{*}$ \\
\hline \multirow{2}{*}{$250 \mathrm{~Hz}$} & UTE & 31.00 & 18.29 & 16.73 & 0.53 \\
\hline & NT & 31.00 & 15.97 & 12.07 & \\
\hline \multirow{2}{*}{$500 \mathrm{~Hz}$} & UTE & 31.00 & 16.45 & 17.47 & 0.79 \\
\hline & NT & 30.00 & 15.33 & 14.26 & \\
\hline \multirow{2}{*}{$1 \mathrm{kHz}$} & UTE & 31.00 & 17.42 & 21.75 & 0.82 \\
\hline & NT & 31.00 & 16.29 & 16.02 & \\
\hline \multirow{2}{*}{$2 \mathrm{kHz}$} & UTE & 31.00 & 17.61 & 18.73 & 0.95 \\
\hline & NT & 31.00 & 17.90 & 17.02 & \\
\hline \multirow{2}{*}{$4 \mathrm{kHz}$} & UTE & 31.00 & 25.65 & 19.91 & 0.81 \\
\hline & NT & 31.00 & 24.32 & 22.47 & \\
\hline \multirow{2}{*}{$6 \mathrm{kHz}$} & UTE & 29.00 & 35.17 & 26.41 & 0.28 \\
\hline & NT & 28.00 & 28.21 & 21.57 & \\
\hline \multirow{2}{*}{$8 \mathrm{kHz}$} & UTE & 31.00 & 35.32 & 27.66 & 0.21 \\
\hline & NT & 30.00 & 27.33 & 21.00 & \\
\hline \multirow{2}{*}{$12 \mathrm{kHz}$} & UTE & 23.00 & 47.83 & 26.23 & 0.39 \\
\hline & NT & 23.00 & 41.09 & 26.41 & \\
\hline \multirow{2}{*}{$16 \mathrm{kHz}$} & UTE & 19.00 & 47.11 & 18.88 & 0.77 \\
\hline & NT & 20.00 & 44.75 & 30.20 & \\
\hline \multirow{2}{*}{ UCL } & UTE & 24.00 & 96.46 & 8.53 & 0.72 \\
\hline & NT & 24.00 & 97.29 & 7.66 & \\
\hline
\end{tabular}

Paired Sample t-test results

Unilateral tinnitus ear (UTE) and no tinnitus (NT)

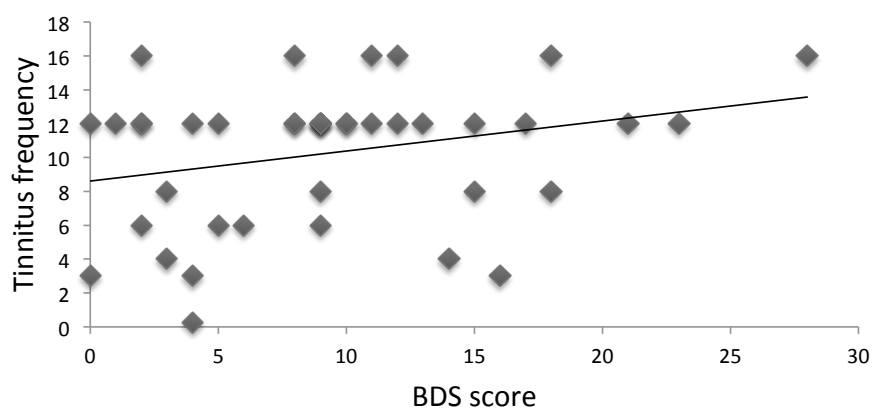

Figure 1. Scatter diagram of BDS versus tinnitus frequency
Wilson et al. indicated that patients with tinnitus feel unhappy, angry and depressive; their sleep and concentration are affected and they are also not ease in social situations [16]. The patients' histories in our study are consistent with those of Wilson's study.

To define the effect of tinnitus on both the patients' and their quality of life, to facilitate standardization, to help the physician during diagnosis and rehabilitation and to see the results of therapy, tinnitus scales are used $[17,18]$. THI and BDS are used in many studies for assessing handicap levels and depression levels $[19,20]$. Crocetti et al. studied 108 patients with tinnitus and found the mean value of THI as 39.76 $( \pm 23.497)$, he also indicated the BDS mean value as $9.97( \pm 8.177)[25]$. These results were similar to our results. Crocetti also stated that BDS scores of the patients who have THI scores higher than 38 and lower than 38 are statistically different from each other. In our study, there was no correlation between BDS and THI scores and the THI level of 38 was not found to be a significant border for BDS scores.

Defining the frequency and intensity level is important for treatment and rehabilitation period and the degree of recovery is assessed by determining the frequency level of the tinnitus [21]. Vernon indicated that $83 \%$ of the patients had tinnitus with frequencies higher than $3000 \mathrm{~Hz}$ [22] and Daumnan et al. indicated that $33 \%$ of the patients have tinnitus with frequencies between $3500-6500 \mathrm{~Hz}$ [23]. Tyler stated that the tinnitus frequency may be at higher frequencies, because the patients have hearing losses at higher frequencies [24]. In our study, although PTA thresholds are at normal levels at lower frequencies, the thresholds are passing the normal borders after $4 \mathrm{kHz}$. The PTA thresholds are increasing through the high frequencies (Table 7 ).

Miguel et al. measured tinnitus frequency and intensity both with the aid of conventional audiometer and high frequency audiometer. Tinnitus frequency levels were found to be higher when a high frequency audiometer was used [14]. In our study, we determined tinnitus frequency and intensity levels using a high frequency audiometer and the mean frequency levels is obtained was $10.33( \pm 4.49) \mathrm{kHz}$.

Miguel et al. also indicated that the patients who have increasing thresholds through higher frequencies, complained more; however there was no connection for tinnitus intensity [14]. In our study, there was a statistically significant correlation between tinnitus frequency and BDS; however, tinnitus intensity was not found to be correlated with BDS scores.

Deniz et al. found that the level of handicap of patients with bilateral tinnitus was more than for patients with 
unilateral tinnitus [10]. In our study, THI scores are significantly different for the patients with unilateral and bilateral tinnitus. Patients with unilateral tinnitus had mean THI scores of $32( \pm 18.42)$ whereas patients with bilateral tinnitus has $51.5( \pm 18.01)$. Patients with unilateral tinnitus had mean BDS scores of $8.67( \pm 6.32)$ and patients with bilateral tinnitus had mean BDS scores of $11.42( \pm 6.79)$. Although BDS scores did not differ statistically, the difference was obviously important clinically, because mean BDS score for patients with bilateral tinnitus passed the border of the normal level.

Tinnitus is comorbid in 50\% of sudden sensory neural hearing loss, $70 \%$ of presbyacusis and $50 \%-90 \%$ of chronical acoustic traumas $[25,26]$. Conducting hearing loss, mixed hearing loss, sensory neural hearing losses do not differ in terms of comorbidity with tinnitus. Intensity and frequency of tinnitus are related to the degree of the hearing loss. We analysed hearing thresholds and UCL scores for both ears of the patients with unilateral tinnitus: thresholds increased through high frequencies for both ears, and there were no differences between the ear with tinnitus and ear without tinnitus (Table 7). This observation implied that the source of tinnitus was central rather than peripheral. We also thought that the central mechanism that was affecting the both ear at equal levels, so the hearing thresholds of both ears, which are measured with the behavioral tests, are the same.

There are many studies about acoustic and perceptual measurement of tinnitus in the literature; however, none assessed both of the parameters together and showed the correlation between the parameters. This cross sectional study was the first for obtaining the relation between audiological assessments and perceptual parameters.

\section{References}

1. Mitchell SM, Mitchael JC. Subspecialty Clinics: Otorhinolaryngology, Tinnitus. Mayo Clin. Proc. 1991; 66: 614-620

2. Kanopka W, Zalewski J, Olszewska-Ziaber, Pietkiewicz P. Tinnitus Suppression by Electrical Promontory Stimulation (EPS) in Patients with Sensörineural Hearing Loss. Auris Nasus Larynx. 2001; 28: 35-40.

3. Noel CA, Meyer WL. Tinnitus: Diagnosis and Treatment of this Elusive Symptom. Geriatrics 2003; 58(2): 28-32.

4. Jastreboff PJ, Gray WC, Mattox DE. Tinnitus and hyperacusis, in Cummings CW (Ed): Otolaryngology Head and Neck Surgery (3rd ed.). Mosby-Year Book, 1998, pp 3198-222.

5. Eggermont JJ. Central Tinnitus. Auris. Nasus Larynx. 2003; 30 (suppl): $7-12$
6. Akyıldız N, Tinnitus, Kulak hastalıkları ve mikrocerrahisi II, Bilimsel tıp yayınevi. Ankara, 2002: 67-81.

7. Karataş E. Subjektif tinnitusta psikolojik ölçme ve deperlendirme yöntemleri. Curr Prackt ORL 2012;8:41-8.

8. Wilson PH, Henry J. Bowen M, Haralambous G. Tinnitus reaction questionnaire: pyscometric properties of a measure of distress associated with tinnitus. J Speech Hear Res 1991;34:197-201

9. Aksoy S, Firat Y, Alpar R. The tinnitus handicap. İnvebtory: a study of validity and reliability. Int Tinnitus 2007;13:94-8.

10. Deniz M, Bayazit YA, Celenk P, Karabulut H, Yilmaz A, Gunduz B, et al. Significance of serotonin transporter gene polymorphism in tinnitus. Otol Neurotol 2010;31:19-24.

11. Fowler Ep. Head noises in normal and disordered ear. Arch Otolaryngol. 1944;39498-503.

12. Feldman H. Homolateral and contralateral masking of tinnitus by noise bands and by pure tones. Audiology. 1911;10:138-44.

13. Vernon J. Relief of tinnitus by masking Treatment. In: English G, Editor. Otolaryngology. Philadelphia: J.B. Lippincott Co.; 1988. Chapter 53.

14. Miguel A. López-Gonzáleza, Esther Cambilb, Antonio Abrantea, Rocío López-Fernándezb, Elizabeth Bareab, Francisco Estebana. Tinnitus Measurement with Conventional Audiometer Versus High-frequency Audiometer. Acta Otorrinolaringólgica Española.2012;63:102-5.

15. Shulman A. Tinnitus Medical Evaluation. Otolaryngologic Clinics of North America 1991; (36) 239-292.

16. Yılmaz M, Erdal EM, Herken H, Çataloluk O, Barlas Ö, Bayazıt YA. Significance Of Serotonin Transporter Gene Polymorphism In Migraine. Journal Of The Neurological Sciences 2001;186: 27-30.

17. Dağlı M, Karabulut H, Eryılmaz A. Tinnitus hastalarının tinnitus derece endeksi ile değerlendirilmesi. $\mathrm{KBB}$ ve $\mathrm{BBC}$ Dergisi 2007;15:12-17.

18. Karabulut H, Acar B, Babademez MA, Tuncay KS, Karaşen RM. Tinnitus tedavisinde intratimpanik deksametazon uygulamasının etkinliği. Anatol J Clin Investig 2009:3:154-8

19. Langguth B, Kleinjung T, Fischer B, Hajak G,Eichhammer P, Sand P.G. Tinnitus severity, depression, and big five personality traits. Progress in Brain Research 2007;166: 221-25

20. Crocetti A, Forti S., Ambrosetti U., Del Bo L. Questionnaires to avaluate anxiety and depressive levels in tinnitus patients, Otology and Neurotology 2009;140;403-5.

21. Cambil E, López-Fernández R, Barea E, Esteban F. In: López González MA, Esteban F, editors. Acúfeno como se nal demalestar. Capítulo 16. Sevilla: Publidisa; 2010., ISBN 978-84692-3367-2 p. 231---42.

22. Vernon, J. Assessment of the Tinnitus Patient". In: Hazell, J., (Eds.). Tinnitus. Edinburgh: Churchill Livingstone; 1987, sayfa: 71-95.

23. Dauman R, Cazals Y. Auditory Frequency Selectivity and Tinnitus. Arch Otorhinolaryngol. 1989; 246: 252-255. 
24. Tyler SR. The Psychoacoustical Measurement of Tinnitus. In: Tyler R, (Eds.). Tinnitus Handbook. San Diego, USA: Singular Pub.; 2000, sayfa: 149-172.

25. Graham JM. Tinnitus and deafness of sudden onset: electrocochleographic finding in 100 patients. J.Laryngol.Otol. 1981;4: 111-6.
26. Spoendlin H. Inner ear pathology and tinnitus. In: Proceedings of The Third International Tinnitus Seminar. Ed. Feldmann H, Munster, Harsch Verlag Karlsrehe, 1987:42-51 